San Jose State University

SJSU ScholarWorks

Doctoral Projects

Master's Theses and Graduate Research

Spring 4-2015

\title{
Sexually Transmitted Disease Education and Effects on Condom Use in College Students
}

\author{
Patricia Alvarez \\ Northern California Consortium, Doctor of Nursing Practice Program, California State University, Fresno \\ and San José State University
}

Follow this and additional works at: https://scholarworks.sjsu.edu/etd_doctoral

Part of the Public Health and Community Nursing Commons

\section{Recommended Citation}

Alvarez, Patricia, "Sexually Transmitted Disease Education and Effects on Condom Use in College Students" (2015). Doctoral Projects. 16.

DOI: https://doi.org/10.31979/etd.wzpu-pz68

https://scholarworks.sjsu.edu/etd_doctoral/16

This Doctoral Project is brought to you for free and open access by the Master's Theses and Graduate Research at SJSU ScholarWorks. It has been accepted for inclusion in Doctoral Projects by an authorized administrator of SJSU ScholarWorks. For more information, please contact scholarworks@sjsu.edu. 
Sexually Transmitted Disease Education and Effects on Condom Use in College Students

\begin{abstract}
In the United States, nearly $50 \%$ of the sexually transmitted diseases (STDs) reported each year occur in adolescents and young adults ages 15-24. An IRB approved, exploratory mix method research study was conducted in a California Community College to investigate participants' opinions on STD education tools, effectiveness, and to rank preferred instructional methods used in $5^{\text {th }}-12^{\text {th }}$ grades. One hundred and thirteen students participated and reported use of variety of educational tools with the lecture technique selected by almost $80 \%$ surveyed. Demonstration of condom application had highest percent ranked as number one for the preferred educational tool; yet had the least percent reported as used in STD education. Incorporation of student's preferred educational tools with the Behavior Change Model can promote self-efficacy and healthy lifestyle choices. Healthcare providers and educators have an opportunity to identify and overcome obstacles that hinder use of tools that provide effective STD education.
\end{abstract}

Key Words: Sexually transmitted diseases (STDs) - STD education and awareness programs- STD prevention - students' preferred educational tools - college students Behavior Change Model

Patricia Alvarez

April 2015 

Sexually Transmitted Disease Education and Effects on Condom Use in College Students

by

Patricia Alvarez

Doctor of Nursing Practice Capstone Project

submitted in partial

fulfillment of the requirements for the degree of

Doctor of Nursing Practice

Northern California Consortium Doctor of Nursing Program

School of Nursing

California State University, Fresno/San Jose

April 2015 

For the Culifomia State University, Northern Californis Consortium Doctor of Nursing Program:

We the undersigned, centify that the Doclor of Nursing Program Capstone Projoct of the following student mects the required standards of sebolarship, format, and style of the university and the student's degree program for the awarding of the Doctor of Nursing Proctice.

Patricia Alvarce

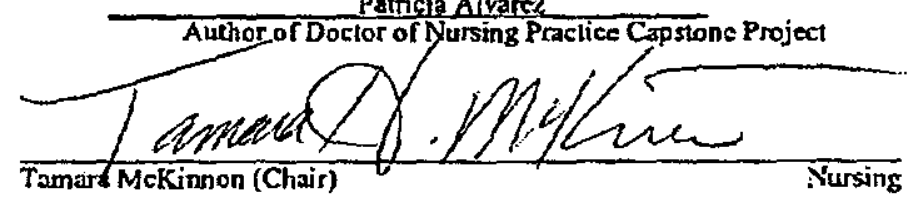

Tamar McKinnon (Chair)

Nursing

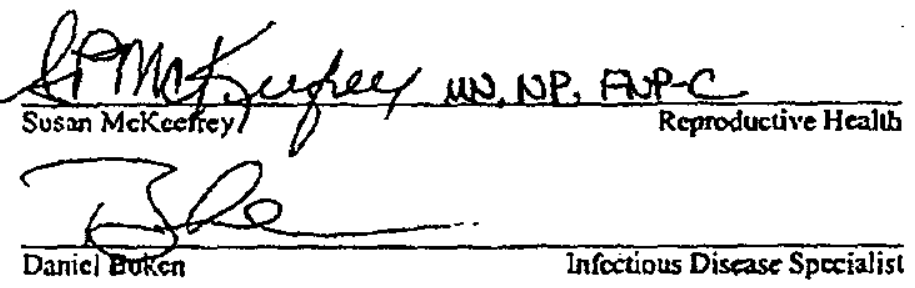

For the University Doelorate Committee:

Dean, Division of Doclorate SIudies 


\section{AUTHORIZATION FOR REPRODUCTION OF CAPSTONE PROJECT}

X_ I grant permission for the reproduction of this capstone project in part or in its entirety without further authorization from me, on the condition that the person or agency requesting reproduction absorbs the cost and provides proper acknowledgment of authorship.

Permission to reproduce this capstone project in part or in its entirety must be obtained from me.

Signature of capstone project author: Patrecen alvary 


\section{ACKNOWLEDGMENTS}

This capstone project would not have been possible without the guidance and assistance of several individuals who contributed their valuable time, knowledge, and skills to assist me in the completion of this research project.

My sincere gratitude and appreciation to my research committee, Dr. Tamara McKinnon, Susan McKeefrey, and Dr. Boken whose expertise, leadership, and encouragement kept me on target and focused on the collection of meaningful data to aid in the improvement of the education and healthcare provided to the population I serve.

I am grateful to my friends, classmates, faculty members, and my advisor Dr. Miller for all the support and guidance provided to me through this challenging journey. A heart-filled thank you to the faculty, staff, administration, and students at my place of employment for being patient, considerate, willing to investigate, and to implement changes to promote health and wellbeing.

Last but not least, love and thanks to my husband Nathan, children, grandchildren, and all of our wonderful family. These words do not express how much I love and appreciate you all for the time, sacrifice, patience and support provided to assist me in achieving this degree. Thank you Lord Jesus for blessing me with all these wonderful people, making the impossible possible, and with the strength and perseverance to earn this degree! 


\section{TABLE OF CONTENTS}

Page

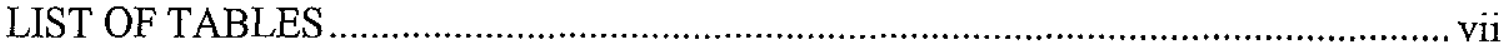

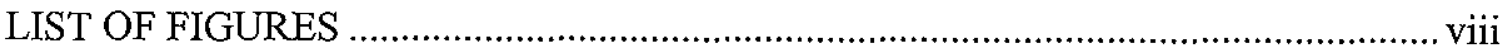

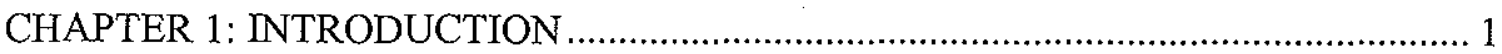

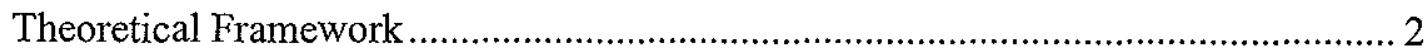

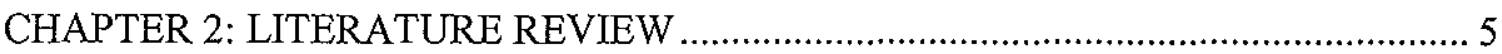

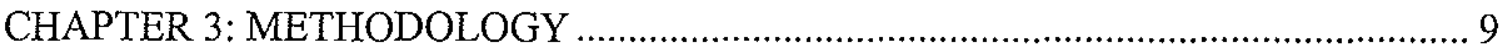

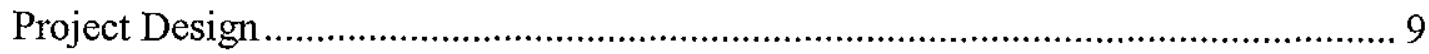

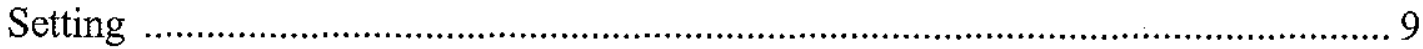

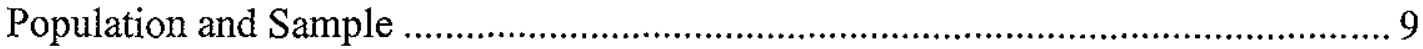

Ethical Consideration ...................................................................................... 9-10

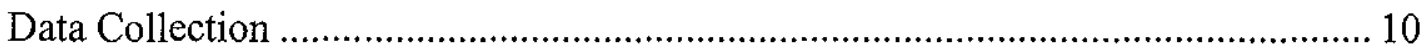

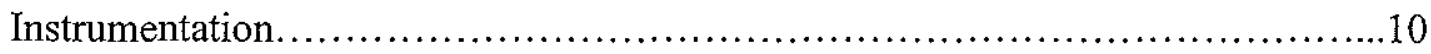

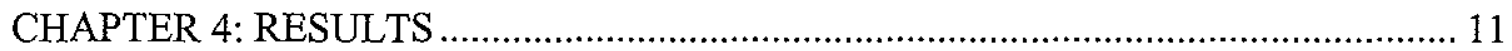

Statistics and Data Analysis....................................................................... 11-18

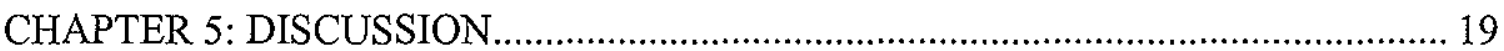

Preferred Educational Methods......................................................................... 20

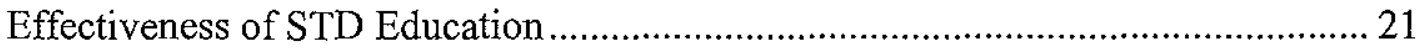

Recommended Educational Methods for each Gender........................................... 23

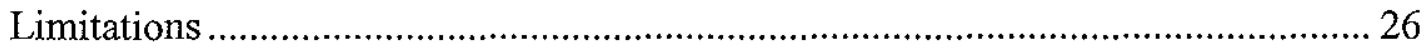

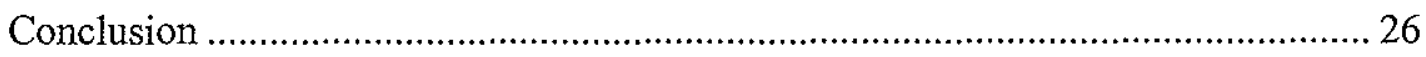

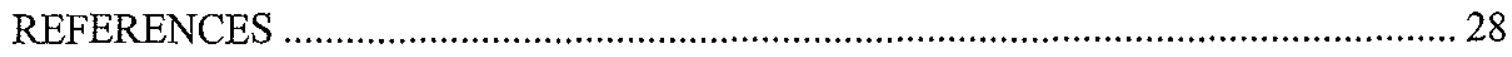

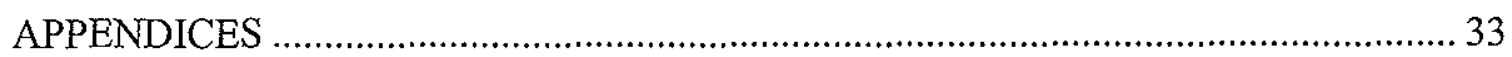

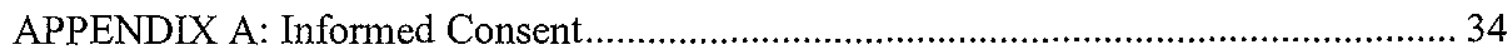

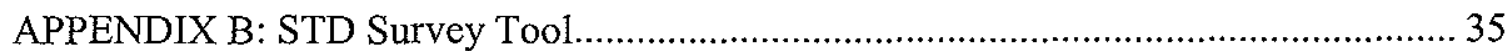




\section{LIST OF TABLES}

Page

Table 1. Frequency and Percent of Participant Demographics........................11

Table 2. Frequency and Percent of Effectiveness of STD Education and Education

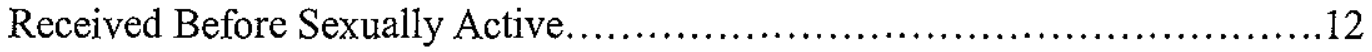

Table 3. Frequency and Percent of Educational Methods Used to Educate on The

Prevention of STD's................................................13

Table 4. Frequency, Mean, and Standard Deviation of the Importance of Educational Methods Used to Educate on the Prevention of STD's.........................14

Table 5. Educational Methods Ranked as Number One_Most Effective in Educating Students in the Prevention of STD's.......................................14

Table 6. Educational Methods Ranked in Order of Importance: \#1 Most Preferred Method and \#9 Least Preferred Educational Method.........................15

Table 7. Frequency and Mean of How to Improve STD Education and Increase Condom

Use among Females. $16-17$

Table 8. Frequency and Mean of How to Improve STD Education and Increase Condom

Use among Males $.17-18$ 


\section{LIST OF FIGURES}

Figure 1: Prochaska, and Velicer (1997). The Transtheoretical Model (TTM) of Behavior Change. ............................................. 3 



\section{Chapter 1: Introduction}

Sexually transmitted diseases (STDs) are health disparities that can infect sexually active individuals at any age. According to the Centers for Disease Control and Prevention (CDC) nearly half of the reported STDs in the United States occur in adolescents and young adults ages 15-24 (CDC, 2013). STD education is one method of promoting awareness and prevention efforts. Despite the STD awareness and prevention programs, reported STDs continue to rise from 19 million in 2010 to 20 million in 2013 (California Department of Public Health, 2011; CDC, 2013). In California schools, abstinence-only education is not permitted; school districts may elect to provide comprehensive sexual health education but are not required to provide STD awareness programs (California Department of Education, 2004; California Department of Education, 2013).

The Comprehensive Sexual Health and HIV/AIDS (Human Immunodeficiency Virus/ Acquired Immunodeficiency Syndrome) Prevention Education Act mandates pupils in grades 7 through 12 to receive age appropriate education to provide knowledge and skills to prevent contraction of HIV/AIDS and to promote healthy attitudes regarding growth and development; however, it does not mandate STD education (California Department of Education, 2004; California Department of Education, 2013). The California Education Codes provides basic guidelines and topics to be reviewed for HIV/AIDS Prevention Education. Unfortunately, the guidelines are vague and implementations of STD education programs differ between educational institutions. Demonstrations of appropriate condom application and use of visual aids displaying active STDs on genitals are not required; many elect not to include this in their 
educational programs (Delgado, 2014). Exclusion of pertinent educational components and topics may be contributing factors to poor condom use in adolescents and young adults. Failure to use condoms and high-risk sexual behaviors are not uncommon in college students which predisposes them to health disparities such as STDs. Utilization of nursing theories and models such as the Stages of Change Model can aid healthcare professionals in identification of health risks and implementation of programs to promote healthy behaviors and well-being (Glanz, Burke, \& Rimer, 2011).

The purpose of this research study is to investigate college students' opinions regarding:

- STD educational tools used in grades $5^{\text {th }}-12^{\text {th }}$

- Perceived effectiveness of STD education

- Preferred instructional methods

The goal is to incorporate findings from this research to improve STD education and promote self-efficacy, healthy behaviors, and condom use in sexually active students.

\section{Theoretical Framework}

Healthcare professionals and educators can apply the Stages of Change Model

(Figure 1.) to identify the stage of readiness and implement strategies that target the area that will promote compliance to the student's decision and readiness to commit to a behavior change (CDC, n.d.). The Transtheoretical Model (TTM) of Behavior Change identifies stages of change and the ten behavioral and cognitive processes that occur during intentional behavior change (Prochaska \& DiClemente, 1983; Prochaska \& Velicer, 1997). The Stages of Change is utilized by healthcare professionals and researchers to implement strategies that guide healthy behavior changes focusing on the 
individual's decision making process as well as their readiness to change (Prochaska \& Velicer, 1997; University of Maryland Baltimore, n.d.).

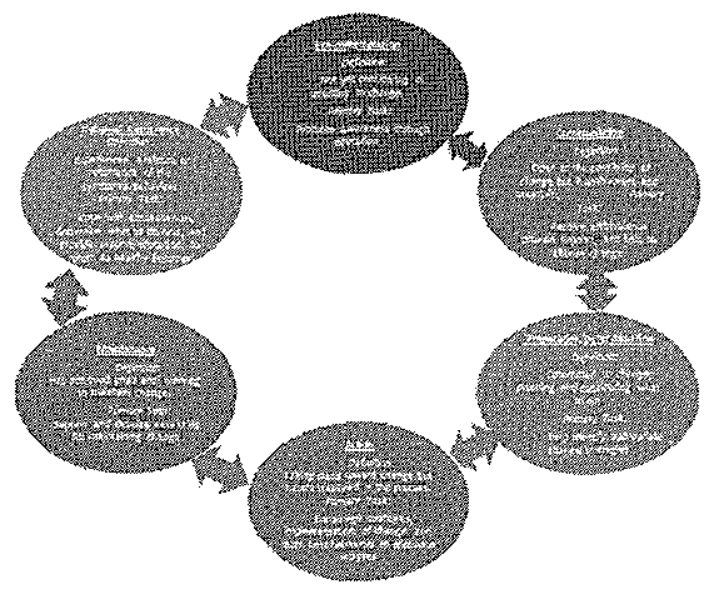

Figure 1.

Prochaska, and Velicer (1997). The Transtheoretical Model (TTM) of Behavior Change.

This model integrates constructs of theories from nursing and psychotherapy, utilizes promotion of healthy behavior change, and is used to investigate the model's effectiveness in various health areas such as prevention of sexually transmitted diseases (Grimley, Riley, Bellis, \& Prochaska, 1993; Prochaska \& Velicer, 1997).

The Transtheoretical Model concentrates on four core constructs: the stage of change (pre-contemplation, contemplation, preparation, action, and maintenance \{termination may be a sixth stage for some behaviors\}), the processes of change (conscious raising, dramatic relief, self-reevaluation, environmental re-evaluation, selfliberation, helping relationships, counter-conditioning, contingency management, stimulus control, and social liberation), decisional balance (exploration of the pros and cons of individual behavior for self and for others), and self-efficacy (Prochaska \& 
DiClemente, 1983). The Stages of Change Model evaluates the client's readiness and comprehension level during each stage, implements specific principles and concepts during the appropriate stage, and promotes self-efficacy. Motivation and planned interventions are crucial to successful behavior change; relapse is a normal occurrence during the process of change (CDC, n.d.; Prochaska \& DiClemente, 1983).

Evaluation and determination of which stage the patient presents is an important step in the process of change. Individuals in the pre-contemplation usually are not considering change; many have experienced unsuccessful behavior change attempts and due to failed attempts have relapsed into the pre-contemplation stage (Prochaska \& DiClemente, 1983; Prochaska \& Velicer, 1997). Others may regard people in this stage as unmotivated or resistant to change but it is no excuse for the clinician to avoid patient education (University of Maryland Baltimore, n.d.). The healthcare professional and educator must take extra care in meeting the needs of the student in this stage by providing non-judgmental feedback, encouragement, and education that promotes awareness to remind the individual that support and assistance is available. The results from the study will be incorporated into a STD educational program utilizing the Behavior Change Model and conduction of a pilot research project to evaluate the effectiveness of STD education program. 


\section{Chapter 2: Literature Review}

Evidenced-based research aids healthcare professionals and educators in identification of problems in planning, implementation, and evaluation of interventions to improve patient care. CDC (2013) reports that STDs increased from 19 million to 20 million indicating current methods of STD awareness and prevention programs are not fully effective. Systematic Review provides researchers with summarization of existing research on a specific topic, question, or intervention/control study; the purpose of the review is to assess the effects of the intervention on a health issue in a population or healthcare setting (Cochrane Consumer Network, 2012). Provision of evidence based medicine (EBM) requires analysis and incorporation of current research findings that provide results that supports the data to implement programs and procedures that improve patient care; systematic reviews can provide this information by providing an overview, results, and benefits or potential harm of numerous studies reviewed by an author on one particular topic/intervention (Akobeng, 2005).

Kim and Free (2008) conducted a systematic review of research regarding peerled education and interventions used to improve sexual outcomes in adolescents. Sciacca (1987) defined peer-led as a method of instruction where a member of a similar age provides instruction or shares information, values, behaviors, and/or beliefs with others in the similar age group or status. The authors reported that they reviewed randomized and quasi-randomized control trials conducted from 1998-2005 that evaluated interventions utilizing peer-led interventions to promote adolescent sexual health, which could be conducted in any setting. The problem of STDs and the effects on the population was 
clearly defined including the information that approximately $60 \%$ of new HIV diagnosis occurs among the 15-24 year olds (Kim and Free, 2008). There were insufficient studies that utilized the same evaluation of outcome measures to determine impact of study quality or bias, intervention components or adherence to the recommendations provided by Harden and colleagues on study effectiveness (Kim and Free, 2008). The systematic review did not reveal overwhelming evidence that peer-led sex education and intervention programs promote positive sexual health behaviors in adolescents. There were positive findings in all studies that peer-led sex education and intervention increase knowledge and attitudes in adolescents regarding sexual health; one study revealed a decrease in Chlamydia in females and another revealed an increase of females that had never had sex. The authors recommend that additional research be conducted on peer-led sex education and interventions with the incorporation of all the criteria of Harden and colleagues to promote a more rigorous way to evaluate effectiveness of peer-led programs.

Carey, Senn, Vanable, Coury-Doniger, and Urban (2010) conducted a study on two groups of participants seeking care at a walk-in STD clinic. Data was collected from both groups. The control group received standard STD education which included brief informational intervention with participant watching a DVD on STD education and the nurse interview asking closed ended questions. The intervention group received counseling using Transtheoretical Model, open ended questions according to stage-ofchange, and intensive education interventions over the 12 month study. The findings 
revealed that participants in the intervention group had a decrease in STDs, number of partners, and episodes of unprotected sex (Carey, et.al, 2010).

A research project conduct by Jozkowski, Geshnizjani, and Middlestadt (2013) investigated healthcare providers' perceptions regarding initiation of discussion on sexual health and disease prevention with female college students in a large mid-west university Health Care Center. The investigators wanted to explore recent findings indicating providers were not following current recommendations for sexual health assessment and education due to feeling uncomfortable with topic or not enough time (Jozkowski,et. al, 2013). Although one provider did express feeling uncomfortable with initiation of conversation because it felt like it was condoning sex outside of marriage, the majority of the providers reported feeling comfortable initiating discussion but felt lack of time made it difficult to provide thorough education. They also noted that healthcare providers (HCP) believed sexual health assessment tools aided in initiating conversation (Jozkowski,et. al, 2013).

The World Health Organization (WHO) provides valuable information and guidelines for practice in preventing and treating sexually transmitted infections (Reproductive Health and Research, 2005). One recommended guideline for healthcare providers was the focus on safety and not on mistrust of partner; discussion of risk factors related to contraction of a STD and the importance of early identification and treatment to prevent complications, benefits both partners. Utilization of data and educational tools from organizations such as WHO, CDC, and Healthy People 2020 can aid healthcare 
providers and educators with implementation of STD awareness and prevention programs.

Kirby (2007) reported research findings comparing comprehensive to abstinence only sex education programs. She described that no federally funded abstinence-only programs have been found to positively impact teen sexual behaviors, reduce the rates of STDs, teen-pregnancies, or initiation of sexual activity (Kirby, 2007). However, a significant majority of the comprehensive sex education programs reviewed are effective, yet receive no comparable federal funding (Kirby, 2007). Kirby (2007) noted delay in the initiation of sex, reduction in the frequency of sex, decrease in sexual partners, and increased condom or contraceptive use as positive outcomes noted from comprehensive sex education programs. Kirby (2007) reports, that research has improved and more has been conducted to reveal persuasive evidence that a limited amount of programs can delay sexual activity, increase contraceptive use, and/or prevent unwanted teen pregnancies. Based on evidenced-based findings, abstinence only sex education is ineffective. The focus should be on mandates to provide comprehensive sexuality education to provide young people and members of society with the tools and information they need to protect themselves and their health (Malone \& Rodriguez, 2011). 


\section{Chapter 3: Methodology}

An exploratory mix method research study was conducted on enrolled students at a California community college in the central valley to investigate participants' opinions of the STD education tools, effectiveness, and preferred instructional methods used in 5th-12th grades. Institutional Review Board (IRB) approval prior to initiation of research was received with minimal risk to human subjects identified. Thirteen hundred, computer-randomized selected students 18 and older were invited through their college email account to participate in this confidential, eleven question survey (Table 1.). The survey was available for completion for a three-week period from October 20 through November 10,2014. An email reminder was sent to the same students one week prior to the conclusion of the survey availability. The survey could be completed only once per student. An Internet tablet was utilized as an incentive prize to participate. Subjects interested in the prize were instructed to print only the "thank you page" from the survey, present it to the college Health Center to receive a ticket stub, and instructed to look on the Health Center door the first week of December for notification of winning ticket. The winner presented the second half of ticket stub and was awarded the prize.

One hundred and thirteen students provided informed consent and participated in the survey. The subjects received an invitation email from the college health center explaining the purpose and description of the study, potential risks, and contact information for additional assistance. In the event that participation in the research project triggered emotional or physical distress, the email included information on college and community resources where subjects could seek services for mental and 
physical health services for counseling, STD testing, and additional education on prevention, diagnosis, and treatment. A link was provided in the email to connect consenting subjects to a secured confidential site to complete the questionnaire on Survey Monkey. Completion of survey implied informed consent. Confidentiality was protected through avoidance of demographic questions that could result in participant identifiers. Data was stored on a secured-server, pass code protected locked computer, and locked in an alarmed office at the college.

\section{Instrumentation}

The eleven-question survey utilized for this study is a tool designed by the research committee. A link was included in the participants' invitation email which connected them directly to the questionnaire on Survey Monkey. The first question was a "yes or no" response to provision of consent. A "yes" response was required in order to advance to the remaining questions on of survey. The next four demographic questions requested information on age, gender, ethnicity, and county residence. The following questions investigated subject response regarding STD education: five questions were multiple choice and ranking, and one short write-in reply. Participants had the option to skip any question after number one. 


\section{Chapter 4: Results}

This study sampled 113 college students from a central California community college regarding the perceived effectiveness of STD education received in grade school. The respondents' demographic responses were in close correlation to the representation of the college population except for gender participation which revealed greater female participation than males; enrollment in the college at the time of survey had $56 \%$ females, $42 \%$ males, and $.009 \%$ non-gender selection. The majority of respondents received STD education in the $7^{\text {th }}$ grade $(26.1 \%$; Table 1$)$.

Table 1.

Frequency and Percent of participant demographics $(N=113)$

\begin{tabular}{lcc}
\hline \multicolumn{1}{c}{ Variable } & $n$ & $\%$ \\
\hline Sex & 82 & \\
$\quad$ Female & 30 & $73.2 \%$ \\
$\quad$ Male & & $26.8 \%$ \\
Ethnicity & 69 & \\
$\quad$ Hispanic / Latino & 26 & $61.1 \%$ \\
$\quad$ White / Caucasian & 8 & $23.0 \%$ \\
$\quad$ Asian & 6 & $7.1 \%$ \\
Multiple Ethnic Groups & 2 & $5.3 \%$ \\
African American / Black & 2 & $1.8 \%$ \\
Native American or Alaska & & $1.8 \%$ \\
Native & & \\
Age Group & 36 & $31.9 \%$ \\
18 to 19 years & 26 & $23.0 \%$ \\
20 to 21 years & 19 & $16.8 \%$ \\
22 to 24 years & 16 & $14.2 \%$ \\
25 to 30 years & 2 & $1.8 \%$ \\
31 to 35 years & 4 & $3.5 \%$ \\
36 to 40 years & 8 & $7.1 \%$ \\
41 to 50 years & 2 & \\
51 to 60 years & & \\
County of residence & 93 & \\
Tulare & &
\end{tabular}




\begin{tabular}{lcc} 
Kings & 18 & $15.9 \%$ \\
$\begin{array}{l}\text { Fresno } \\
\text { Grade Level }\end{array}$ & 2 & $1.8 \%$ \\
$5^{\text {th }}$ or $6^{\text {th }}$ grade & 26 & \\
$7^{\text {th }}$ grade & 29 & $23.4 \%$ \\
$8^{\text {th }}$ grade & 11 & $26.1 \%$ \\
$9^{\text {th }}$ grade & 24 & $9.9 \%$ \\
$10^{\text {th }}$ grade & 6 & $21.6 \%$ \\
$11^{\text {th }}$ grade & 0 & $5.4 \%$ \\
$12^{\text {th }}$ grade & 1 & $0.0 \%$ \\
Did not receive STD education & 4 & $0.9 \%$ \\
Do not remember & 9 & $4.5 \%$ \\
\hline
\end{tabular}

Approximately $60 \%$ of the respondents indicated they believed the STD education they received in grade school was effective and nearly $81 \%$ received this education before becoming sexually active (Table 2 ).

Table 2.

Frequency and Percent of study variables $(N=113)$

\begin{tabular}{lcc}
\hline \multicolumn{1}{c}{ Variable } & $n$ & $\%$ \\
\hline STD education effective & & \\
Yes & 66 & $59.5 \%$ \\
No & 28 & $25.2 \%$ \\
Unsure / Don't Know & 17 & $15.3 \%$ \\
Receive STD Education before sexually active & & \\
Yes & 67 & $60.9 \%$ \\
Not sexually active, have received STD & 22 & $20.0 \%$ \\
education & & \\
No & 15 & $13.6 \%$ \\
Do not remember & 5 & $4.5 \%$ \\
Not sexually active, have not received STD & 1 & $0.9 \%$ \\
education & & \\
\hline
\end{tabular}

The educational methods most frequently received on the prevention of STD's are contained in table 3 . Respondents on this question were allowed to select any number of 
the educational methods they received on the prevention of STD's. The most frequent educational method was lecture (76.1\%), followed by pictures of STD patients and DVD/Videos, $58.4 \%$ and $53.1 \%$, respectively.

Table 3.

Frequency and Percent of educational methods used to educate on the prevention of STD's $(N=113)$

\begin{tabular}{lcc}
\hline \multicolumn{1}{c}{ Variable } & $n$ & $\%$ \\
\hline Lecture & 86 & $76.1 \%$ \\
Pictures of STD diseases & 66 & $58.4 \%$ \\
DVD / Videos & 60 & $53.1 \%$ \\
PowerPoint / projector slides & 59 & $52.2 \%$ \\
Educational Handouts & 53 & $46.9 \%$ \\
Visual Aids (posters, models, & 49 & $43.4 \%$ \\
etc.) & 46 & $40.7 \%$ \\
Group Discussion / Q\&A session & 24 & $21.2 \%$ \\
Demonstrate condom application & 5 & $4.4 \%$ \\
Do not remember & &
\end{tabular}

The educational method believed to be most effective in educating students on the prevention of STD's is presented in Table 4. The education method believed to be most effective by the respondent is the presentation of pictures of STD diseases on patients ( $M$ $=4.67, S D=3.088)$ and demonstration of proper condom application $(M=4.67, S D=$ 3.286). Students were instructed to label in order of importance methods they believed are most effective in educating students on prevention of STDs. 
Table 4.

Frequency, Mean, and Standard Deviation of the importance of educational methods used to educate on the prevention of STD's $(N=113)$

\begin{tabular}{lccc}
\hline \multicolumn{1}{c}{ Variable } & $n$ & $M$ & $S D$ \\
\hline Pictures of STD diseases & 109 & 4.67 & 3.088 \\
Demonstrate condom application & 106 & 4.67 & 3.286 \\
Visual Aids (posters, models, etc.) & 107 & 4.62 & 2.993 \\
DVD / Videos & 105 & 4.55 & 2.642 \\
Educational Handouts & 108 & 4.55 & 2.859 \\
Group Discussion / Q\&A session & 106 & 4.46 & 3.021 \\
PowerPoint / projector slides & 109 & 4.42 & 2.671 \\
Lecture & 109 & 4.36 & 2.641 \\
\hline
\end{tabular}

Demonstration of proper condom application, group discussion, and pictures of STDs had the highest percentages ranked as number one in educational methods to teach students on how to prevent sexually transmitted diseases (Table 5.) Table 6. reveals the students responses in ranking educational methods from most preferred to least

Table 5.

Educational methods ranked as number one most effective in educating students in the prevention of STD's.

\begin{tabular}{lcc}
\hline \multicolumn{1}{c}{ Variable } & $n$ & $\%$ \\
\hline Demonstrate condom application & 32 & $30.19 \%$ \\
Group Discussion / Q\&A session & 28 & $26.42 \%$ \\
Pictures of STD diseases & 28 & $25.69 \%$ \\
Visual Aids (posters, models, etc.) & 24 & $22.43 \%$ \\
Lecture & 22 & $20.18 \%$ \\
Educational Handouts & 20 & $18.52 \%$ \\
PowerPoint / projector slides & 19 & $17.43 \%$ \\
DVDs/Videos & 16 & $15.42 \%$ \\
\hline
\end{tabular}


Table 6. Educational methods ranked in order of importance: \#1 most preferred method and \#9 least preferred educational method.

Frequency and Percent of Preferred Ranking Order of Educational Methods on Preventing Sexually Transmitted Diseases

\begin{tabular}{lllllllllll} 
Rank & 1 & 2 & 3 & 4 & 5 & 6 & 7 & 8 & 9 & Total \\
\hline
\end{tabular}

Demonstration of Proper Condom Application $\quad 30.19 \% \quad 8.49 \% \quad 9.43 \% \quad 3.77 \% \quad 4.72 \% \quad 6.60 \% \quad 4.72 \% \quad 8.49 \% \quad 23.58 \%$

$\mathrm{n}=32 \quad \mathrm{n}=9 \quad \mathrm{n}=10 \quad \mathrm{n}=4 \quad \mathrm{n}=5 \quad \mathrm{n}=7 \quad \mathrm{n}=5 \quad \mathrm{n}=9 \quad \mathrm{n}=25 \quad 106$

Group Discussion:Question and Answers Sessions 26.42\% 14.15\% 4.72\% $\quad 4.72 \% \quad 13.21 \% \quad 4.72 \% \quad 6.60 \% \quad 11.32 \% 14.15 \%$

$n=28 \quad n=15 \quad n=5 \quad n=5 \quad n=14 \quad n=5 \quad n=7 \quad n=12 \quad n=15 \quad 106$

Pictures of Sexually Transmitted Diseases on $\quad 25.69 \% \quad 10.09 \% \quad 9.17 \% \quad 6.42 \% \quad 6.42 \% \quad 4.59 \% \quad 8.26 \% \quad 13.76 \% 15.60 \%$

$\begin{array}{lllllllllll}\text { Patients } & \mathrm{n}=28 & \mathrm{n}=11 & \mathrm{n}=10 & \mathrm{n}=7 & \mathrm{n}=7 & \mathrm{n}=5 & \mathrm{n}=9 & \mathrm{n}=15 & \mathrm{n}=17 & 109\end{array}$

Visual Aids such as Posters, Models, and Samples 22.43\% 14.02\% 7.48\% 6.54\% 7.48\% 11.21\% 6.54\% 6.54\% $17.76 \%$

$\mathrm{n}=24 \quad \mathrm{n}=15 \quad \mathrm{n}=8 \quad \mathrm{n}=7 \quad \mathrm{n}=8 \quad \mathrm{n}=12 \quad \mathrm{n}=7 \quad \mathrm{n}=7 \quad \mathrm{n}=19 \quad 107$

Lecture $\quad 20.18 \% 8.26 \% 13.76 \% 11.01 \% 18.35 \% \quad 7.34 \% \quad 3.67 \% \quad 4.59 \% 12.84 \%$

$n=22 \quad n=9 \quad n=15 \quad n=12 \quad n=20 \quad n=8 \quad n=4 \quad n=5 \quad n=14 \quad 109$

Educational Handouts, Pamphlets, and Bookets $\quad$ 18.52\% $14.81 \% \quad 13.89 \% \quad 3.70 \% \quad 12.04 \% \quad 6.48 \% \quad 7.41 \% \quad 9.26 \% \quad 13.89 \%$

$n=20 \quad n=16 \quad n=15 \quad n=4 \quad n=13 \quad n=7 \quad n=8 \quad n=10 \quad n=15 \quad 108$

PowerPoint Presentationsi Overhead

$17.43 \% 13.76 \% 13.76 \% 9.17 \% \quad 9.17 \% \quad 11.01 \% 9.17 \% \quad 5.50 \% 11.01 \%$

Projector/Sides $n=19 \quad n=15 \quad n=15 \quad n=10 \quad n=10 \quad n=12 \quad n=10 \quad n=6 \quad n=12 \quad 109$

DVDsNideos

$15.24 \% 12.38 \% 15.24 \% 10.48 \% 8.57 \% 11.43 \% 6.67 \% 10.48 \% 9.52 \%$

$\mathrm{n}=16 \quad \mathrm{n}=13 \quad \mathrm{n}=16 \quad \mathrm{n}=11 \quad \mathrm{n}=9 \quad \mathrm{n}=12 \quad \mathrm{n}=7 \quad \mathrm{n}=11 \quad \mathrm{n}=10 \quad 105$

An independent samples $t$ test was conducted to determine a significant difference on the belief that demonstration of condom application is an effective educational method between respondents who had and had not received a demonstration of condom application as part of their STD education. Using the Levene's test for equality of 
variances correction, an independent samples $t$ test indicated no significant difference on the belief that demonstration of condom application is an effective educational method between respondents who had $(M=3.91, S D=2.859, n=23)$ and had not $(M=4.88, S D$ $=3.380, n=83)$ received a demonstration of condom application as part of their STD education, $t(40.70)=1.376, p=.176$. Despite believing that demonstration of proper condom application is one of the most effective STD educational methods $(M=4.64, S D$ $=3.286$ ), proper condom application was only received by $21.2 \%$ of students; the least frequently method for educating students on STD prevention.

As part of this study, there was one qualitative question regarding how to improve STD education and increase condom use. Respondents were asked to provide one suggestion for each gender. Responses on how to improve STD education and increase condom use for females are presented in table 7. Analysis of responses indicated seven main themes, with an equal number of respondents suggesting that information on the reality of teen pregnancy and STDs to include pictures and videos and more education on STDs and contraceptives would improve STD education and increase condom use. Of the respondents who responded to the question, six people provided responses that were not on topic.

Table 7.

Frequency and Mean of how to improve STD education and increase condom use among females $(N=62)$

\begin{tabular}{lcc}
\hline \multicolumn{1}{c}{ Theme } & $n$ & $\%$ \\
\hline $\begin{array}{l}\text { Information of the reality of teen } \\
\text { pregnancy and STDs, including pictures }\end{array}$ & 22 & $35.5 \%$
\end{tabular}


and stories

Education on STDs and contraceptives methods

Promote abstinence if not unable to use condom

Provide free contraceptives to individuals in need Provide education on non-penetrative / alternative sexual practices Promote abstinence all together
22

11

3

2

1

1
$35.5 \%$

$17.7 \%$

$4.8 \%$

$3.2 \%$

$1.6 \%$

$1.6 \%$

Responses on how to improve STD education and increase condom use for males are presented in table 8 . Analysis of responses indicated six main themes, with the majority of respondents suggesting that more education on STDs and contraceptives would improve STD education and increase condom use. Of the respondents who responded to the question, ten people provided responses that were not on topic. No responses were aimed at promoting complete abstinence for males.

Table 8 .

Frequency and Mean of how to improve STD education and increase condom use among males $(N=57)$

\begin{tabular}{|c|c|c|}
\hline Theme & $n$ & $\%$ \\
\hline Education on STDs and contraceptives & 29 & $50.9 \%$ \\
\hline $\begin{array}{l}\text { Information of the reality of teen } \\
\text { pregnancy and STDs, including pictures } \\
\text { and stories }\end{array}$ & 17 & $29.8 \%$ \\
\hline $\begin{array}{l}\text { Open dialogue and alternative education } \\
\text { methods }\end{array}$ & 7 & $12.3 \%$ \\
\hline $\begin{array}{l}\text { Provide education on non-penetrative / } \\
\text { alternative sexual practices }\end{array}$ & 2 & $3.5 \%$ \\
\hline
\end{tabular}


Running head: STD EDUCATION EFFECTS ON CONDOM USE

Provide free contraceptives to individuals

1

$1.8 \%$

in need

Promote abstinence if not unable to use condom 


\section{Chapter 5: Discussion and Conclusion}

There were no research studies found that investigated students' perceptions on use of various educational tools and their effectiveness compared with students preferred and ranking order of these instructional tools. Participants in this study reveal the use of various tools and media in STD education. A high percent of non-interactive instructional tools are noted as frequently utilized in STD education. Lecture was identified by this sample as the most common instructional tool used in STD education. Knowledge and comfort level with this sensitive topic may be reasons why STD educators utilize these forms more frequently. Lecture allows the educator to do all the talking with or without student input. Activities such as demonstration of correct condom application and group discussion were utilized least often. Teaching strategies that are interactive promote comprehension, student participation, and a partnership in the learning process between the student and instructor (Billings \& Halstead, 2012). The instructor sets the tone in the classroom setting. If the educator is uncomfortable with the topic it can hinder students from asking questions and seeking clarification of topics presented by the instructor; thus decreasing the effectiveness of the education.

Utilization of various tools to educate on STD prevention is important. Each student has preferred learning styles. The findings from this study can aid school nurses and educators to improve selection of educational techniques and encourage use of preferred learning tools with Behavior Change Model to support student readiness to make healthy reproductive behavior choices and change. The ultimate goal is for school nurses and educators serving in middle schools and high schools to utilize these findings 
to assess and incorporate their student population preferred learning styles into their STD. HIV/AIDS and prevention of unwanted pregnancy awareness programs. Provision of effective education in these areas can delay first sexual encounter and empower the students with skills and knowledge to make healthy behavior choices.

\section{Preferred Educational Methods}

This study revealed students prefer teaching strategies that promote interaction i.e. demonstration on condom application, STD pictures, and group discussion to educate on STDs. Instead, the tools utilized the most for these participants were lecture, STD pictures, DVDs, and power point presentations which ultimately only require the student to sit, listen, and watch as the presenter educates the classroom.

It is not enough to have a STD awareness program in schools. The findings from this study reveal the importance of incorporating educational methods that promote comprehension and healthy behaviors. STD programs must provide teaching strategies that meet the learning needs of the students in order to be effective. Activities that promote learning include group discussion, games that encourage students to match signs and symptoms with names and pictures of STDs, and role play of case scenarios to promote development of skills to make healthy behaviors and choices. It is concerning that the highest percent of students selected demonstration of condom application as the number one rank for preferred instructional tool, yet it was reported as an instructional tool used the least in this study. How can instructors effectively educate on the importance of condom use in the prevention of STDs but fail to demonstrate how to apply a condom correctly on a model? The students in this study have reported their 
needs; it is crucial that healthcare providers and educators utilize the evidence-based research to implement effective programs to meet the needs of their student population!

\section{Effectiveness of STD Education}

Nearly $60 \%$ of the subjects reported the STD education received was effective. Twenty-five percent of the respondents selected that it was not effective and $15 \%$ were uncertain. If students' are uncertain, STD educators should be concerned that there is the potential for up to $40 \%$ reporting that the education program was ineffective. Almost half of the 20 million reported STDs occur in individuals ages 15-24; possible correlation to this statistic is that up to $40 \%$ of the students in this study are reporting ineffective STD education. This should be a real concern for school nurses and educators responsible for providing effective STD education.

Nearly $81 \%$ indicated STD education was provided prior to first sexual encounter with $20 \%$ reporting not sexually active during time of survey. This sample indicates that STD education is being offered for the majority of students at a time that provides education prior to sexual experimentation. Unfortunately, nearly $15 \%$ percent did not receive STD education prior to first sexual encounter with one subject reporting not sexually active at time of survey. Those that did not receive the education could have been missed due to absence, parental refusal to participate, or attendance at a school that did not offer STD education. These questions cannot be answered by this study. Age of initiation of first sexual encounter differs among individuals. Approximately $23 \%$ of the participants in this study revealed that they had STD education in $5^{\text {th }}-6^{\text {th }}$ grades. Introduction to age appropriate STD education should be carefully considered as early as 
in $5^{\text {th }}$ and $6^{\text {th }}$ grades. Obstacles that prevent or hinder provision of effective comprehensive STD education in $7^{\text {th }}-12^{\text {th }}$ grades should be identified and reduced.

Revisions to the education codes to comply with state and federal laws to provide rights to minors 12 and older to receive STD, HIV/AIDS, and prevention of unwanted pregnancy education under the teen reproductive health regulations may resolve this dilemma. Annual presentations of this material may also reduce the number of students missed due to absence on day of programs only offered twice from middle school through high school. Most education codes currently require parental consent for student participation in these programs. Parent participation is an important factor in the provision of effective reproductive health education. It should be encouraged but parents should not be allowed to dictate or prohibit the provision of evidence-based and age appropriate STD education. Misconceptions regarding STD education include: STD pictures viewed by some as pornographic material, STD pictures are used as a source of scare tactics to reduce students' sexual encounters, and fear that STD education promotes sexual activity (Gautam-Adhikary, 2011)

STD facts are scary and presentation of this information is not intended to be used as scare tactics but to inform and provide the students with the knowledge and skills to avoid becoming one of the statistics. STDs infect genitals through sexual contact. Pictures of genitals with STDs are utilized to increase knowledge and prevention of exposure and not used to elicit sexual arousal when in fact it can have the opposite effect. Demonstration of condom application on a medical model is not used to promote sexual activity in students. The intent of comprehensive STD education is to provide: age 
appropriate education to develop knowledge and skills to prevent contraction of STDs which includes abstinence as the only sure way to prevent infection, delay first sexual encounter, promote healthy attitudes regarding growth and development, promote monogamous relationships and limited partners in sexually active individuals, and encourage condom use and STD testing in sexually active people (CDC, 2013). The goal is to empower the students with knowledge, skills, and respect for self and others to make informed reproductive health decisions.

Students will be exposed to some type of STD education in schools. Education can be provided by peers, Internet, media, potential sexual partner, or trained professionals. Educators should partner with parents to provide reassurance and clarification on purpose and importance of educational tools utilized to provide effective STD education. Parents of students who are adamant that their child will not have sex prior to marriage should be comforted with the fact that the education their student receives can be utilized by their child to empower their decision and aid in the peer to peer education process.

\section{Qualitative Student Recommendations on STD Education for Each Gender}

Student recommendations to provide more effective STD education and improve condom use in females tied for first place requesting the provision of information on the reality of teen pregnancy with inclusion of pictures and stories (35.5\%) and education on STDs and contraceptives (35.5\%). Open dialogue and alternative education methods were second and encouraged by $17.7 \%$ of the students. Subjects from this study report the importance of discussing teen pregnancy with STDs and prevention methods. Use of 
pictures, group discussion, and guest speakers that can share their story regarding STD infections and/or teen pregnancy are methods this sample believe would increase condom use. Comments by students include:

"Teach them that it's their body to do as they see fit. And they are in charge of maintaining it healthy. Not to rely on men to use condoms. Not to fall for lies men tell them to get out of using one."

"Show girls how to properly put on a condom; emphasize that girls can go out and buy condoms too, it's not just a male's job to do so."

"I think that having people (who have STDs) come in and talk about their own experiences might have more impact on the students than the teacher alone could."

"Teach them it is ok to have condoms and suggest their mate uses one." "I think STD education should start in junior high if not before and be open about it and in a way to show teen girls to be responsible and be educated about their body."

"Demonstration of using condoms properly."

"Discussion on how STDs can affect your baby."

"STD teaching should be taught more than once." "Photos of infected people."

Similar recommendations to improve STD education and increase condom use in males were provided but in different order of importance. Nearly $60 \%$ discussed the importance of education on STDs and contraceptives; followed by information of the 
reality of teen pregnancy and STDs with the inclusion of pictures and stories $(29.8 \%)$. Open dialogue and alternative education methods were recommended by $12.3 \%$. Once again the students are reporting the importance of STD education, reality of teen pregnancy, and requesting use of pictures, guest speakers, and open dialogue. Comments by students:

"Show examples of syphilis and other diseases from sexual activity." "...bring in people whose lives were changed by not using protection." "More visual pictures of all the diseases, videos of how someone suffered from a terrible disease."

"Bring in guest speakers who have recovered from a sexually transmitted disease."

"Use small groups to get the message across." "Demonstration and pictures of STDS."

"Talk about condom use every year during middle school/high school, so men are not so shy about buying and wearing them."

"More pictures."

"Show how to use. Discuss consequences of unprotected sex. Statistical data on STD's."

Respondents in this study are indicating the importance of showing them pictures of STDs, demonstration of correct condom application, use of guest speakers to share personal experience of infection and teen pregnancy, and discussion on these topics. If lecture is the primary tool of STD education, it is time to review and revise the program. 
These students are reporting they want alternative forms of education and discussion that promotes talking with them and not to them about STDs.

\section{Limitations}

The participants surveyed represents a small sample from one community college in California. Conservative communities and/or rural areas may have different results than metropolitan areas that may be more liberal in discussing STDs and prevention efforts. This research project did not investigate or compare educational environments such as individual versus group education, health fairs, classroom, peer-peer counseling, or separation of genders during STD education which could be a critical component in providing effective STD education. Replication of this study in various demographic settings throughout the US with the addition of a question to evaluate preferred educational environment is strongly recommended.

\section{Conclusion}

There is no one simple solution to the alarming percent of STDs reported each year in the adolescent and young adult populations. State laws regulating minors reproductive healthcare vary but Title $\mathrm{X}$ provides federal regulations to decrease barriers faced by adolescents regarding parental consent, confidentiality, and financial obligations. STD education is a vital component in reproductive health. State and federal laws should be compared with the education codes and revised for compliance. Revision of education codes to allow minors 12 and older to participate in comprehensive STD education without parental consent can reduce obstacles faced by many to provide various activities that promote effective education. Adoption of a state-wide STD, 
HIV/AIDS, and prevention of unwanted pregnancies education programs with clearly defined curriculum, evidence-based, age-appropriate, CDC approved, and delivered annually by qualified nurses or health educators can also aid in the delivery of effective education. The findings from this study provides a vehicle to give the sample of this student population a voice to inform school nurses and educators of the effectiveness and preferred learning activities in STD education. School districts are strongly encouraged to assess their student population, incorporate findings into their STD programs, and remove obstacles that prevent provision of effective STD education to this high-risk population. 


\section{References}

Akobeng, A. K. (2005). Understanding Systematic reviews and meta-analysis. Arch Dis

Child, 90, 845-848. http://adc.bmj.com/content/90/8/845.full.pdf+html

Billings, D. M., \& Halstead, J. A. (2012). Teaching in nursing a guide for faculty (4th

ed.). St. Louis, MA: Elsevier.

California Department of Education. (2004). Comprehensive Sexual Health and

HIV/AIDS Prevention Education Act. Retrieved from http://www.cde.ca.gov/ls/he/se/

California Department of Education. (2013). HIV/AIDS Prevention Program.

Retrieved from http://www.cde.ca.gov/ls/he/se/hivaidsprevention.asp

California Department of Public Health. (2011). Sexually transmitted diseases in

California 2011. Center for Infectious Diseases Division of Communicable Disease

Control, Sexually Transmitted Disease Control Branch. Retrieved from

http://www.cdph.ca.gov/data/statistics/Pages/STDData.aspx

Carey, M., Senn, T., Vanable, P., Coury-Doniger, P., \& Urban, M. (2010). Brief and intensive behavioral interventions to promote sexual risk reduction among STD clinic patients: results from a randomized controlled trial. AIDS \& Behavior, Centers for Disease Control and Prevention. (n.d.). Community and individual behavior change interventions. Program Operation Guidelines for STD Prevention. Retrieved 
from http://www.cdc.gov/std/program/community.pdf

Centers for Disease Control and Prevention. (2013). Sexually Transmitted Disease:

Adolescents and Young Adults. Retrieved from http://www.cdc.gov/std/life-stages-

populations/adolescents-YoungAdults.htm

Cochrane Consumer Network. (2012). What is a systematic review? Retrieved from

http:/consumers.cochrane.org/what-systematic-review

Dreweke, J. (2007). Guttmacher advisory: review of key findings of "emerging answers

2007" report on sex education programs. Guttmacher Institute. Retrieved from

http:// guttmacher.org/.../2007/11/07/Advisory_Emerging_Answers_2007.pdf

Delgado, Jasmin. "HIV/STD Update for Educators." County Office of Education School

Health Programs [Conference]. California, 11 April 2014.

Gautam-Adhikary, S., D. (2011). Myths and facts about comprehensive sex education:

Research contradicts misinformation and distortions. Advocates for Youth. Retrieve

from http://advocateesforyouth.org/storage/

Glanz, K., Burke, L. E., \& Rimer, B. K. (2011). Health behavior theories. In J. B. Butts

\& K. L. Rich (Eds). Philosophies and Theories for Advanced Nursing Practice.

Sudbury, Ma: Jones \& Barlett Learning.

Jozkowski, K. N., Geshnizjani, A., \& Middlestadt, S. E. (2013). University health

center providers' beliefs about discussing and recommending sexual health 
Running head: STD EDUCATION EFFECTS ON CONDOM USE

prevention to women college students. Health Educator, 45(1), 22-30.

Grimley, D.M., Riley, G.E., Bellis, J.M., \& Prochaska, J.O. (1993). "Assessing the stages of change and decision-making for contraceptive use for the prevention of pregnancy, sexually transmitted diseases, and acquired immunodeficiency syndrome." Health Education Quarterly 20(4): 455-470.

Kim, C. R. \& Free, C. (2008). Recent evaluations of the peer-led approach in adolescent sexual health education: A systematic review. International Family Planning Perspectives, 34, 2, 89- 96.

Kirby, D. (2007). Emerging answers 2007: Research findings on programs to reduce teen pregnancy and sexually transmitted diseases. The National Campaign to Prevent Teen and Unplanned Pregnancies. Retrieved from http://thenationalcampaign.org/resource/emerging-answers-2007\%E2\%80\%94fullreport

Malone, R \& Rodriguez, M. (2011). Comprehensive sex education vs. abstinence-onlyuntil- marriage programs. Human Rights Magazine 38 (2). Retrieved from http:/www.americanbar.org/publications/human rights magazine home/human rights vol38 2011/human rights spring2011/comprehensive sex education vs abstinence on1 y until marriage programs.html

Prochaska, J.O. \& DiClemete, C.C. (1983). Stages and processes of self-change of 
Running head: STD EDUCATION EFFECTS ON CONDOM USE smoking: Toward an integrative model of change. Journal of Counseling and Clinical Psychology, 51(3), 390-395.

Prochaska, J.O. \& Velicer, W.F. (1997).The transtheoretical model of health behavior change. American Journal of Health Promotion, 12(1), 38-48.

Reproductive Health and Research. (2005). Integrating STI/RTI care for reproductive health: A guide to essential practice. World Health Organization. Retrieved from http://www.who.int/reproductivehealth/topics/rtis/evidence/en/

Sciacca, J.P. (1987). Student peer health education: a powerful yet inexpensive helping strategy, Peer Facilitator Quarterly, 1987, 5(2):4-6

University of Maryland Baltimore. (n.d.). The transtheoretical model of behavior change. HABITS Lab Psychology Department. Retrieved from http:/www.umbc.edu/psyc/habits/content/the_model/ 
Running head: STD EDUCATION EFFECTS ON CONDOM USE

APPENDICES 


\section{APPENDIX A: INFORMED CONSENT FORM}

\section{Informed Consent to Participate}

You are being asked to participate in a survey research project entitled "Sexually Transmitted Disease Education and Effects on Condom Use in College Students," which is being conducted by Patricia Alvarez MSN, RN, APHN-BC, a faculty member and Student Services Health Coordinator at XXXXXXXXXXXXXXX. This survey is anonymous. No one, including the researcher, will be able to associate your responses with your identity.

The purpose of this study is to obtain participant's views and information regarding sexually transmitted disease education received in grade school $5^{\text {th }}$-12th and the effectiveness in influencing condom use as a college student. Although you may find some of the questions embarrassing or briefly upsetting, there are no anticipated longterm risks to you related to your participation in this study. Some of the questions in this survey may cause you to recall unpleasant or emotionally upsetting experiences. If you feel you need to speak with a healthcare professional regarding possible sexually transmitted disease exposure, testing, or for additional health education or questions, you may contact $X X X X X X X X X X X X X X$ Student Health Center at $X X X X X X X X X X$ or Planned Parenthood at $X X X X X X X X X X X$ for help.

Your participation in this survey is voluntary and anonymous. You may choose not to take the survey, to stop responding at any time, or to skip any questions that you do not want to answer. You must be at least 18 years of age to participate in this study. Your completion of the survey serves as your voluntary agreement to participate in this research project and your certification that you are 18 or older.

Questions regarding the purpose or procedures of the research should be directed to Patricia Alvarez at XXXXXXXXXXX or XXXXXXXXXXXXX. This study has been exempted from Institutional Review Board (IRB) review in accordance with Federal regulations. The IRB, a university committee established by Federal law, is responsible for protecting the rights and welfare of research participants. If you have concerns or questions about your rights as a research participant, you may contact Dr. XXXXXXXX the Director of Research, Planning, and Institutional Effectiveness at XXXXXXXXXXX or XXXXXXXXXXX. Completion of this survey implies informed consent to participate in this research project. 


\section{APPENDIX B: STD SURVEY TOOL}

\section{Sexually Transmitted Disease Education and Effects on Condom Use in}

\section{College Students Survey}

Completion of this survey implies informed consent to participate in this research project. Participants who desire mental health counseling, nursing assessment, sexually transmitted disease testing, or additional education may contact their personal healthcare provider, local healthcare facility, or the student Health Center at $x x x-x x x-x x x x x$.

1. I understand and agree to participate in this Survey?
- Yes
○ No

\section{Gender \\ - Male \\ - Female}

○ Other: Pease Specify

\section{Ethnicity/Race}

- White/Caucasian

- Hispanic/Latino

- African American/Black

- Native American or Alaska Native

- Native Hawaiian or other Pacific Islander

- Asian

- Other: Please Specify
4. Age
- 18-19
- 20-21
- 22-24
- 25-30
- 31-35
- $36-40$ 
- $41-50$

- 51-60

- 61 or older

5. County where you live

- Tulare County

- Kings County

- Fresno County

- Kern County

- Madera County

- Other: Please specify

6. What grade level did you first receive sexually transmitted disease education in school?

- $5^{\text {th }}-6^{\text {th }}$ grades

- $7^{\text {th }}$ grade

- $8^{\text {th }}$ grade

- $9^{\text {th }}$ grade

- $10^{\text {th }}$ grade

- $11^{\text {th }}$ grade

- $12^{\text {th }}$ grade

- Did not receive sexually transmitted disease education in a school setting

- Do not remember

7. What types of educational methods were used to educate you on prevention of sexually transmitted diseases? (Check all that apply)

- Lecture

- Power Point Presentations/overhead projector and slides

- DVD/Videos

- Group discussion/Question and answer sessions

- Pictures of sexually transmitted diseases on patients

- Demonstration of proper condom application

- Visual aids such as posters, models, and various birth control methods

- Educational handouts, pamphlets, and booklets

- Other: Please Specify

- Do not remember 
8. Label in order of importance methods you believe are most effective in educating students on prevention of sexually transmitted disease (For instance, if you believe lecture is the most effective way to teach student on prevention of sexually transmitted disease then place 1 by lecture, if you believe it is the least effective way to teach students on how to prevent sexually transmitted disease then place 8 next to lecture).

\begin{tabular}{|l|c|c|c|c|c|c|c|c|c|}
\hline \multicolumn{1}{|c|}{ Educational Tools } & Score & 1 & 2 & 3 & 4 & 5 & 6 & 7 & 8 \\
\hline & & & & & & & & & \\
\hline Lecture & & & & & & & & \\
\hline Power PointPresentations/overhead projector/sides & & & & & & & & & \\
\hline DVo/Nideos & & & & & & & & & \\
\hline Group discussion/Question and answer sessions & & & & & & & & & \\
\hline Pictures of sexually transmitted diseases on patients & & & & & & & & & \\
\hline Demonstration of proper condom application & & & & & & & & & \\
\hline Visual aids such as posters, models, and samples & & & & & & & & & \\
\hline Educational handouts, pamphlets, and booklets & & & & & & & & & \\
\hline
\end{tabular}

9. Do you feel the sexually transmitted disease education that you received in school was effective helping you make healthy choices regarding sexually health and disease prevention?

○ Yes

- No

- Unsure/Do not know

10. Did you receive sexually transmitted disease education in school prior to becoming sexually active?

○ Yes

- No

- Do not remember

- Not sexually active; have received STD education

- Not sexually active; have not received STD education 
11. Please provide one suggestion or more suggestions for each gender on how teachers can improve sexually transmitted disease education to increase condom use in males and females?

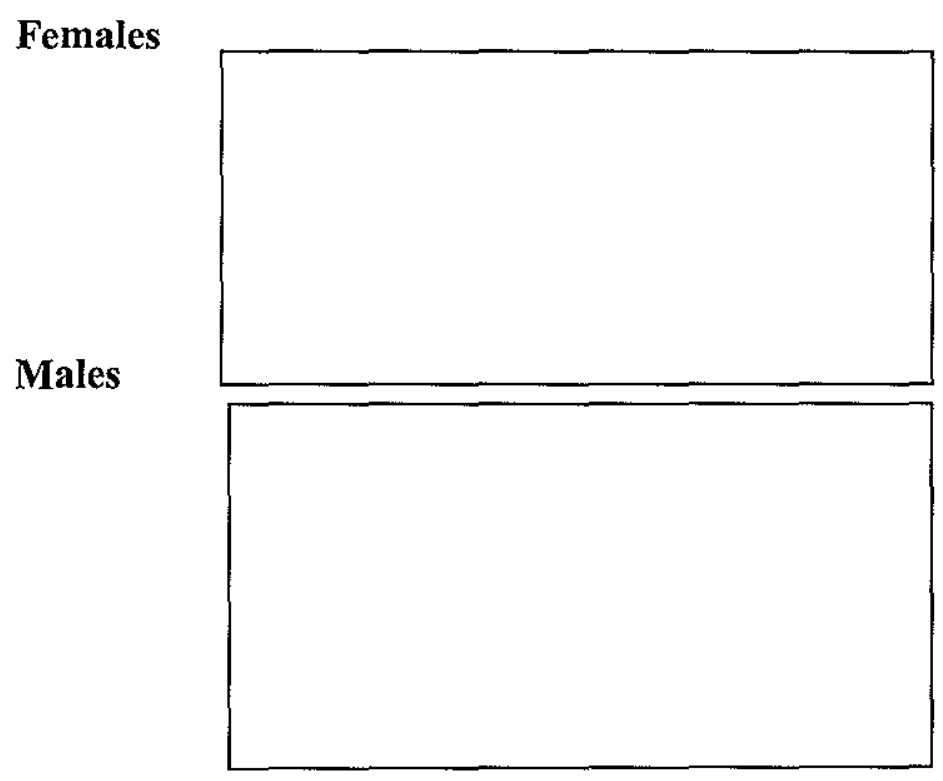


This concludes the survey. Thank you for your time and participation!!! Please print and present only this page to the college Health Center for a chance to win an internet tablet. Participants will be given one half of a ticket stub. A copy of the winning ticket stub will be placed on the Health Center door the first week in December. Winner must present with second half of ticket to pick up prize. 